\title{
ANHARMONIC PROPERTIES OF ALKALI HALIDES AND CYANIDES
}

\author{
KAILASH \\ Department of Physics, B.N.V.College, Rath, Hamirpur, U.P., 210431, India
}

(Received August 1, 1995)

\begin{abstract}
Anharmonic properties of 16 alkali halides and 4 alkali cyanides are investigated using long-range Coulomb and short-range Börn-Mayer potentials starting from the nearest-neighbour distance and repulsive parameter. This study includes the prediction of second, third and fourth order elastic constants, the pressure derivatives of second and third order elastic constants and partial contractions at elevated temperatures. The results obtained in present investigations are in reasonable agrecment compared with experimental studies.
\end{abstract}

PACS numbers: $62.20 . \mathrm{Dc}, 81.40 . \mathrm{Jj}$

\section{Introduction}

The elastic energy density for a deformed crystal can be expanded as a power series of strains and the coefficients of quadratic, cubic and quartic terms are known as second, third and fourth order elastic constants (SOEC, TOEC and FOEC), respectively. When the values of SOEC, TOEC and FOEC are known for a crystal, many of the anharmonic properties of the lattice can be treated within the limit of the continuum approximation in a quantitative manner. Crystal anharmonicities such as thermal expansion, high temperature specific heat, temperature variation of acoustic velocity and attenuation, first order pressure derivatives of SOEC, Grüneisen numbers and temperature derivatives of SOEC are directly related to SOEC and TOEC. While discussing higher order anharmonicities such as the first order pressure derivatives of TOEC, the second order pressure derivatives of SOEC, deformation of crystals undèr large forces and partial contractions, FOEC are to be considered extensively.

In recent years, some efforts have been made in studying the elastic properties of materials of different kinds [1-7]. Some fruitful work has been done by various investigators while studying the anharmonic properties of solids of several types. They have studied temperature dependence of SOEC of rare gas solids [8], of some alkali halides [9], of a few alkali cyanides using ultrasonic [10-12] and Brillouin scattering $[13,14]$ methods and of mixed alkali halide cyanide crystals 
[15]. The theoretical evaluations of TOEC of a few alkali halides $[16,17]$, chalcogenides [18], rare gas solids [8, 19] and fluorite crystals [20] have been done by some workers. TOEC of $\mathrm{NaCN}$ and $\mathrm{KCN}$ are measured by Haussühl et al. [21] at $293 \mathrm{~K}$. Few efforts have been made while investigating FOEC of crystals of various natures $[7,16,17,22]$. No complete theoretical or experimental efforts have been so far made in obtaining the temperature variation of SOEC, TOEC and FOEC, pressure derivatives of SOEC and TOEC and partial contractions of alkali halides and cyanides.

The present theory deals with the formulation for evaluating SOEC, TOEC and FOEC at any temperature, the first order pressure derivatives of SOEC and TOEC, second order pressure derivatives of SOEC and partial contractions assuming long-range Coulomb and short-range Börn-Mayer potentials starting from the nearest-neighbour distance and repulsive parameter. The results are tabulated for all alkali halides and cyanides of the rock salt structure.

\section{Formulation}

The elastic strain energy density for a crystal of a cubic symmetry can be expanded up to quartic terms as follows [23]:

$$
\begin{aligned}
& U_{0}= U_{2}+U_{3}+U_{4} \\
&=\frac{1}{2 !} C_{i j k l} x_{i j} x_{k l}+\frac{1}{3 !} C_{i j k l m n} x_{i j} x_{k l} x_{m n}+\frac{1}{4 !} C_{i j k l m n p q} x_{i j} x_{k l} x_{m n} x_{p q} \\
&=\frac{1}{2} C_{11}\left(x_{11}^{2}+x_{22}^{2}+x_{33}^{2}\right)+C_{12}\left(x_{11} x_{22}+x_{22} x_{33}+x_{33} x_{11}\right) \\
&+2 C_{44}\left(x_{12}^{2}+x_{23}^{2}+x_{31}^{2}\right)+\frac{1}{6} C_{111}\left(x_{11}^{3}+x_{22}^{3}+x_{33}^{3}\right) \\
&+\frac{1}{2} C_{112}\left[x_{11}^{2}\left(x_{22}+x_{33}\right)+x_{22}^{2}\left(x_{33}+x_{11}\right)+x_{33}^{2}\left(x_{11}+x_{22}\right)\right] \\
&+C_{123} x_{11} x_{22} x_{33}+2 C_{144}\left(x_{11} x_{23}^{2}+x_{22} x_{31}^{2}+x_{33} x_{12}^{2}\right) \\
&+2 C_{166}\left[x_{12}^{2}\left(x_{11}+x_{22}\right)+x_{23}^{2}\left(x_{22}+x_{33}\right)+x_{31}^{2}\left(x_{33}+x_{11}\right)\right] \\
&+8 C_{456} x_{12} x_{23} x_{31}+\frac{1}{24} C_{1111}\left(x_{11}^{4}+x_{22}^{4}+x_{33}^{4}\right) \\
&+\frac{1}{6} C_{1112}\left[x_{11}^{3}\left(x_{22}+x_{33}\right)+x_{22}^{3}\left(x_{33}+x_{11}\right)+x_{33}^{3}\left(x_{11}+x_{22}\right)\right] \\
&+\frac{1}{4} C_{1122}\left(x_{11}^{2} x_{22}^{2}+x_{22}^{2} x_{33}^{2}+x_{33}^{2} x_{11}^{2}\right) \\
&+\frac{1}{2} C_{1123} x_{11} x_{22} x_{33}\left(x_{11}+x_{22}+x_{33}\right) \\
&+C_{1144}\left(x_{11}^{2} x_{23}^{2}+x_{22}^{2} x_{31}^{2}+x_{33}^{2} x_{12}^{2}\right) \\
&+C_{1155}\left[x_{11}^{2}\left(x_{31}^{2}+x_{12}^{2}\right)+x_{22}^{2}\left(x_{12}^{2}+x_{23}^{2}\right)+x_{33}^{2}\left(x_{23}^{2}+x_{31}^{2}\right)\right] \\
&+2 C_{1255}\left[x_{11} x_{22}\left(x_{23}^{2}+x_{31}^{2}\right)+x_{22} x_{33}\left(x_{31}^{2}+x_{12}^{2}\right)+x_{33} x_{11}\left(x_{12}^{2}+x_{23}^{2}\right)\right] \\
&+2 C_{1266}\left(x_{11} x_{22} x_{12}^{2}+x_{22} x_{33} x_{23}^{2}+x_{33} x_{11} x_{31}^{2}\right) \\
&+8 C_{1456} x_{12} x_{23} x_{31}\left(x_{11}+x_{22}+x_{33}\right)+\frac{2}{3} C_{4444}\left(x_{12}^{4}+x_{23}^{4}+x_{31}^{4}\right) \\
&
\end{aligned}
$$




$$
+4 C_{4455}\left(x_{12}^{2} x_{23}^{2}+x_{23}^{2} x_{31}^{2}+x_{31}^{2} x_{12}^{2}\right)
$$

where $C_{i j k l}, C_{i j k l m n}$ and $C_{i j k l m n p q}$ are SOEC, TOEC and FOEC in tensorial form, $x_{i j}$ are the Lagrangian strain components, $C_{I J}, C_{I J K}$ and $C_{I J K L}$ are SOEC, TOEC and FOEC in Brügger's definition [24] and Voigt notations.

The elastic constants of the second, third and fourth order are defined as [24]

$$
\begin{aligned}
& C_{i j k l}=C_{I J}=\left(\frac{\partial^{2} U}{\partial x_{i j} \partial x_{k l}}\right)_{x=0}, \\
& C_{i j k l m n}=C_{I J K}=\left(\frac{\partial^{3} U}{\partial x_{i j} \partial x_{m n} \partial x_{k l}}\right)_{x=0}
\end{aligned}
$$

and

$$
C_{i j k l m n p q}=\left(\frac{\partial^{4} U}{\partial x_{i j} \partial x_{k l} \partial x_{m n} \partial x_{p q}}\right)_{x=0} .
$$

The free energy density $[25,26]$ of a crystal at a finite temperature $T$ is

$$
U_{\text {Total }}=U_{0}+U^{\mathrm{vib}}, \quad U^{\mathrm{vib}}=\frac{k T}{N V_{\mathrm{c}}} \sum_{i=1}^{3 s N} \ln 2 \sinh \left(\frac{\hbar \omega_{i}}{k T}\right),
$$

where $U_{0}$ is the internal energy per unit volume of the crystal when all ions are at rest on their lattice points, $U^{\mathrm{vib}}$ is the vibrational free energy, $V_{\mathrm{c}}$ is the volume of the primitive cell, $N$ is the number of the primitive cells in the crystal and $s$ is the number of ions in the elementary cell. Other notations used in this equations have their usual meanings.

An elastic constant can be separated into two parts:

$$
C_{I J}=C_{I J}^{0}+C_{I J}^{\mathrm{vib}}, C_{I J K}=C_{I J K}^{0}+C_{I J K}^{\mathrm{vib}}
$$

and

$$
C_{I J K L}=C_{I J K L}^{0}+C_{I J K L}^{\mathrm{vib}} .
$$

The first part is the strain derivative of the internal energy $U_{0}$ and is known as "static" elastic constant and the second part is the strain derivative of the vibrational free energy $U^{\text {vib }}$ and is called "vibrational" elastic constant. The superscript " 0 " has been introduced to emphasize that the static elastic constants correspond to absolute zero temperature.

The energy density of the nondeformed crystal is expressed as

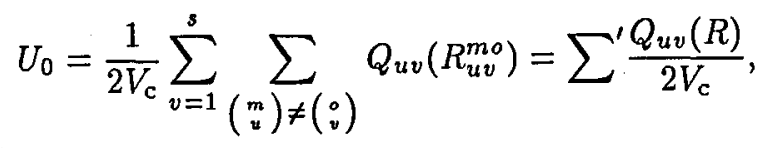

where $R_{u v}^{m o}$ is the distance between the $v$-th ion in the $a$-th cell and the $u$-th ion in the $m$-th cell and $Q_{u v}$ is the interaction potential between the ions. The indices $(v, o)$ and $(u, m)$ are sometimes dropped when no confusion occurs. One assumes that $Q_{u v}$ is the sum of the electrostatic and the Börn-Mayer [27] short-range repulsive potentials

$$
Q_{u v}(R)= \pm\left(e^{2} / R\right)+A \exp (-R / q)
$$


where $e$ is the electric charge, \pm signs apply to like and unlike ions, respectively and $A$ and $q$ are some parameters. One includes the short-range interactions up to the second nearest-neighbours. The general expressions for the short-range interactions up to the second nearest-neighbours will be of three types:

(i) unlike ions: $A_{+-} \exp \left(-r_{1} / q_{+-}\right)$,

(ii) like positive ions: $A_{++} \exp \left(-r_{2} / q_{++}\right)$,

(iii) like negative ions: $A_{--} \exp \left(-r_{2} / q_{--}\right)$.

Such a model would require six parameters. One further assumes that $A$ and $q$ are the same for all short-range interactions, where $q$ is the repulsive parameter of the crystal and $A$ is given by

$$
A=-0.29126 q\left(e^{2} / r_{0}^{4}\right) /\left[\exp \left(-r_{0} / q\right)+2 \sqrt{2} \exp \left(-r_{0} \sqrt{2} / q\right)\right] .
$$

When the crystal is deformed homogeneously, the distance between $(v, o)$ and $(u, m)$ ion in the deformed and nondeformed states, $R_{u v}^{m o}$ and $r_{u v}^{m o}$, are related to the Lagrangian strains $x_{i j}$ as follows:

$$
\left(R_{u v}^{m o}\right)^{2}-\left(r_{u v}^{m o}\right)^{2}=2 Y_{u v i}^{m o} Y_{u v j}^{m o} x_{i j}=2 Z_{u v}^{m o}
$$

where $Y_{u v i}^{m o}$ is the $i$-th Cartesian component of the vector $r_{u v}^{m o}$. The definition of the quantity $Z_{u v}^{m o}$ is also expressed in Eq. (8). The internal energy $U_{0}$ given by Eq. (5) can be expanded in terms of $Z$, which yields quadratic, cubic and quartic terms as shown below

$$
\begin{aligned}
U_{2} & =\frac{1}{2 V_{c}} \sum^{\prime}\left[\frac{Z^{2} D^{2} Q(R)}{2 !}\right]_{R=r}=\frac{1}{4 V_{c}}\left[x_{i j} x_{k l} \sum^{\prime} Y_{i} Y_{j} Y_{k} Y_{l} D^{2} Q(R)\right]_{R=r^{\prime}}, \\
U_{3} & =\frac{1}{2 V_{c}} \sum^{\prime}\left[\frac{Z^{3} D^{3} Q(R)}{3 !}\right]_{R=r} \\
& =\frac{1}{12 V_{c}}\left[x_{i j} x_{k l} x_{m n} \sum^{\prime} Y_{i} Y_{j} Y_{k} Y_{l} Y_{m} Y_{n} D^{3} Q(R)\right]_{R=r}, \\
U_{4} & =\frac{1}{2 V_{c}} \sum^{\prime}\left[\frac{Z^{4} D^{4} Q(R)}{4 !}\right]_{R=r} \\
& =\frac{1}{48 V_{c}}\left[x_{i j} x_{k l} x_{m n} x_{p q} \sum^{\prime} Y_{i} Y_{j} Y_{k} Y_{l} Y_{m} Y_{n} Y_{p} Y_{q} D^{4} Q(R)\right]_{R=r}
\end{aligned}
$$

with the abbreviation $D=\frac{d}{(R \mathrm{~d} R)}$. With reference to Eqs. (3) and (4) and comparison of Eqs. (1) and (9), one obtains the static elastic constants which are shown in Table I (all tables are collected in Sec. 5).

For a central force model, there are only two independent SOEC, three independent TOEC and four independent FOEC at $0 \mathrm{~K}$.

As in the case of the internal energy $U_{0}$, the vibrational free energy is also expanded in terms of strains; the quadratic, cubic and quartic terms are as below

$$
\begin{aligned}
& U_{2}=\frac{1}{V_{c} 2 !} \sum^{\prime} \sum^{\prime}\left[Z Z^{\prime}\left(D^{\prime} D\right) U^{\mathrm{vib}}\right]_{Z=0}=\frac{1}{2 V_{c}} x_{i j} x_{k l} f_{i j k l}, \\
& U_{3}=\frac{1}{V_{c} 3 !} \sum^{\prime} \sum^{\prime} \sum_{\prime \prime}^{\prime}\left[Z Z^{\prime} Z^{\prime \prime}\left(D^{\prime \prime} D^{\prime} D\right) U^{\mathrm{vib}}\right]_{Z=0}=\frac{1}{6 V_{c}} x_{i j} x_{k l} x_{m n} f_{i j k l m n},
\end{aligned}
$$




$$
\begin{aligned}
U_{4} & =\frac{1}{V_{c} 4 !} \sum^{\prime} \sum_{\prime}^{\prime} \sum_{\prime \prime}^{\prime} \sum_{m \prime}^{\prime}\left[Z Z^{\prime} Z^{\prime \prime} Z^{\prime \prime \prime}\left(D^{\prime \prime \prime} D^{\prime \prime} D^{\prime} D\right) U^{\mathrm{vib}}\right]_{Z=0} \\
& =\frac{1}{24 V_{c}} x_{i j} x_{k l} x_{m n} x_{p q} f_{i j k i m n p q}
\end{aligned}
$$

where

$$
\begin{aligned}
& f_{i j k l}=\sum^{\prime} \sum_{\prime}^{\prime}\left[Y_{i} Y_{j} Y_{k}^{\prime} Y_{l}^{\prime}\left(D^{\prime} D\right) U^{\mathrm{vib}}\right]_{R=r} \\
& f_{i j k l m n}=\sum^{\prime} \sum_{\prime}^{\prime} \sum_{\prime \prime}^{\prime}\left[Y_{i} Y_{j} Y_{k}^{\prime} Y_{l}^{\prime} Y_{m}^{\prime \prime} Y_{n}^{\prime \prime}\left(D^{\prime \prime} D^{\prime} D\right) U^{\mathrm{vib}}\right)_{R=r}
\end{aligned}
$$

and

$$
f_{i j k l m n p q}=\sum^{\prime} \sum_{l}^{\prime} \sum_{\prime \prime}^{\prime} \sum_{i \prime \prime}^{\prime}\left[Y_{i} Y_{j} Y_{k}^{\prime} Y_{l}^{\prime} Y_{m}^{\prime \prime} Y_{n}{ }^{\prime \prime} Y_{p}{ }^{\prime \prime \prime} Y_{q}^{\prime \prime \prime}\left(D^{\prime \prime \prime} D^{\prime \prime} D^{\prime}\right) U^{\mathrm{vib}}\right]_{R=r} .
$$

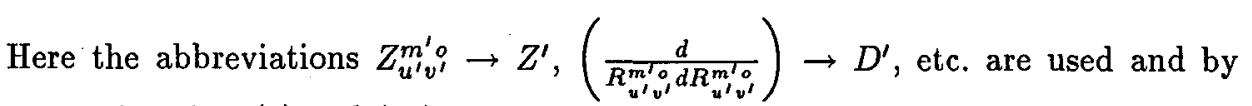
comparing Eqs. (1) and (10), one can determine the vibrational elastic constants. These are given in Table II. These are shown as a combination of $g_{n}$ and $F_{n}$ which are evaluated conveniently by taking crystal's symmetry [28] into account and the expressions for $g_{n}$ and $F_{n}$ are shown in Table III. By adding the vibrational elastic constants to the static elastic constants, one may get SOEC, TOEC and FOEC at any temperature.

The first order pressure derivatives of SOEC are related to SOEC and TOEC, the first order pressure derivatives of TOEC and second order pressure derivatives of SOEC are concerned with SOEC, TOEC and FOEC and partial contractions are mere combinations of FOEC. The expressions for the pressure derivatives [29, 30] and partial contractions $[31,32]$ are given in Tables IV and $V$, respectively.

\section{Evaluation}

Using the concept of the nearest-neighbour distance $[28,33]$ and repulsive parameter $[17,34]$, the SOEC, TOEC and FOEC are computed at $0 \mathrm{~K}$ (Table I) and are given in Table VI for different alkali halides and cyanides. The temperature coefficients $F_{n}$ (Table III) are also evaluated and are shown in Table VII. The calculated values of SOEC, TOEC and FOEC at $300 \mathrm{~K}$ adding the vibrational contributions are presented in Tables VIII and IX. The first order pressure derivatives of SOEC and TOEC, second order pressure derivatives of SOEC and partial contractions using room temperature data are investigated and are given in Tables $\mathrm{X}$ and $\mathrm{XI}$.

\section{Results and discussions}

Tables VIII and IX show that there are three independent SOEC, six independent TOEC and eleven independent FOEC for halides and cyanides of alkali metals at room temperature. The experimental values of SOEC and TOEC are in good agreement for alkali halides and differ in a certain ratio for alkali cyanides. One may obtain better results to a certain extent by changing the repulsive parameter. Due to the lack of experimental studies of FOEC no comparison can be 
made. The first order pressure derivatives of SOEC (Table X) are also in reasonable agreement with the experimental results. The values of the first order pressure derivatives of TOEC may be of help for other workers in further investigations. The experimental data of the second order pressure derivatives of SOEC for some alkali halides are available which are in good agreement for rubidium halides and are in reasonable agreement for sodium halides (Table XI). The overall good agreement between theoretical and experimental investigations supports the validity of the interaction model used in the present work.

\section{Tables*}

TABLE I

Expressions for the second, third and fourth order elastic constants at $0 \mathrm{~K}$.

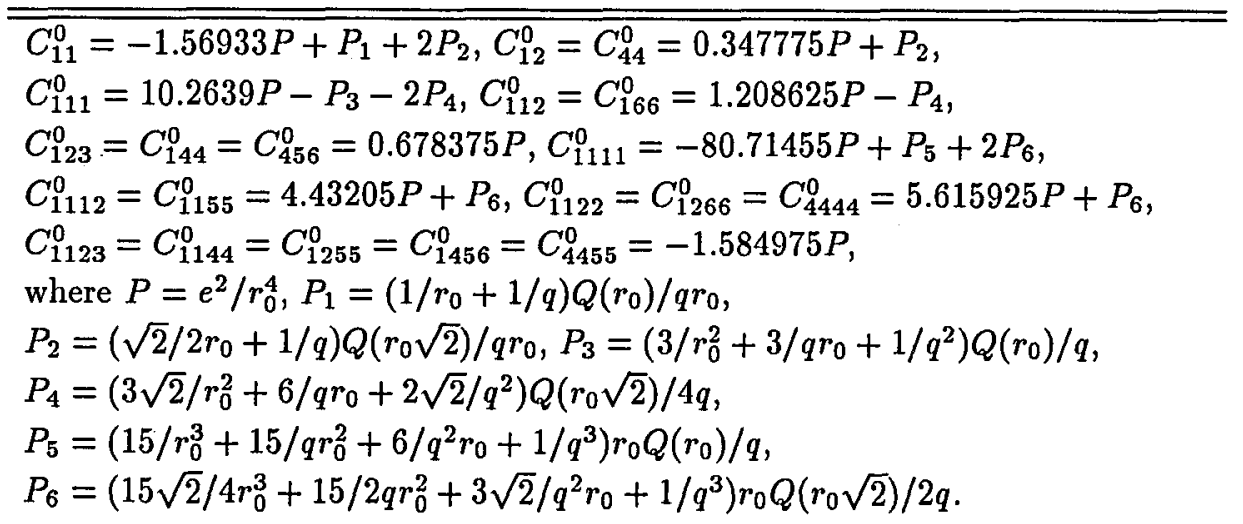

TABLE II

Expressions for vibrational contribution to the second, third and fourth order elastic constants.

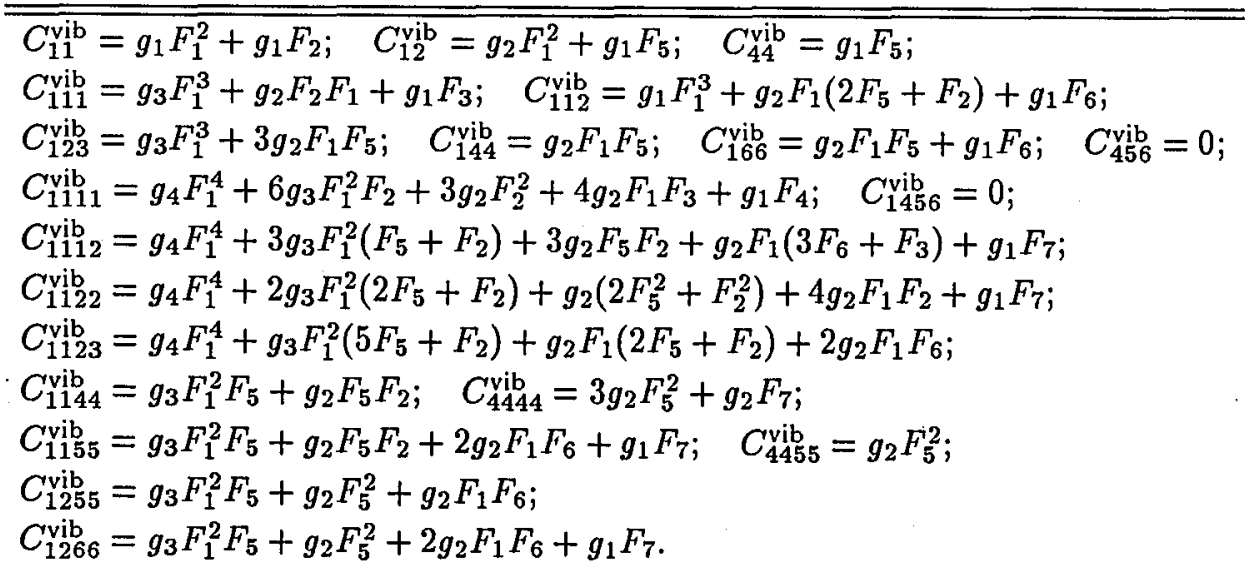

*For technical reasons the tables are not given in their numerical order. 
Expressions for $g_{n}$ and $F_{n}$.

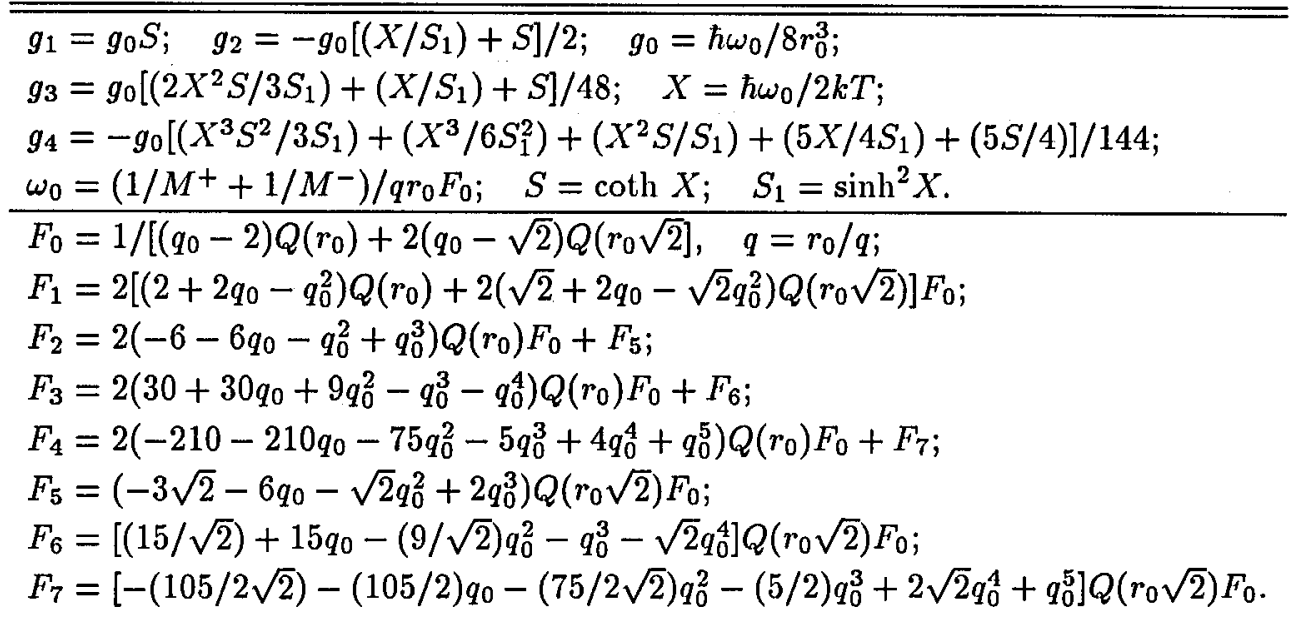

TABLE IV

Expressions for the first order pressure derivatives of the second and third order elastic constants and expressions for the second order pressure derivatives of the second order elastic constants.

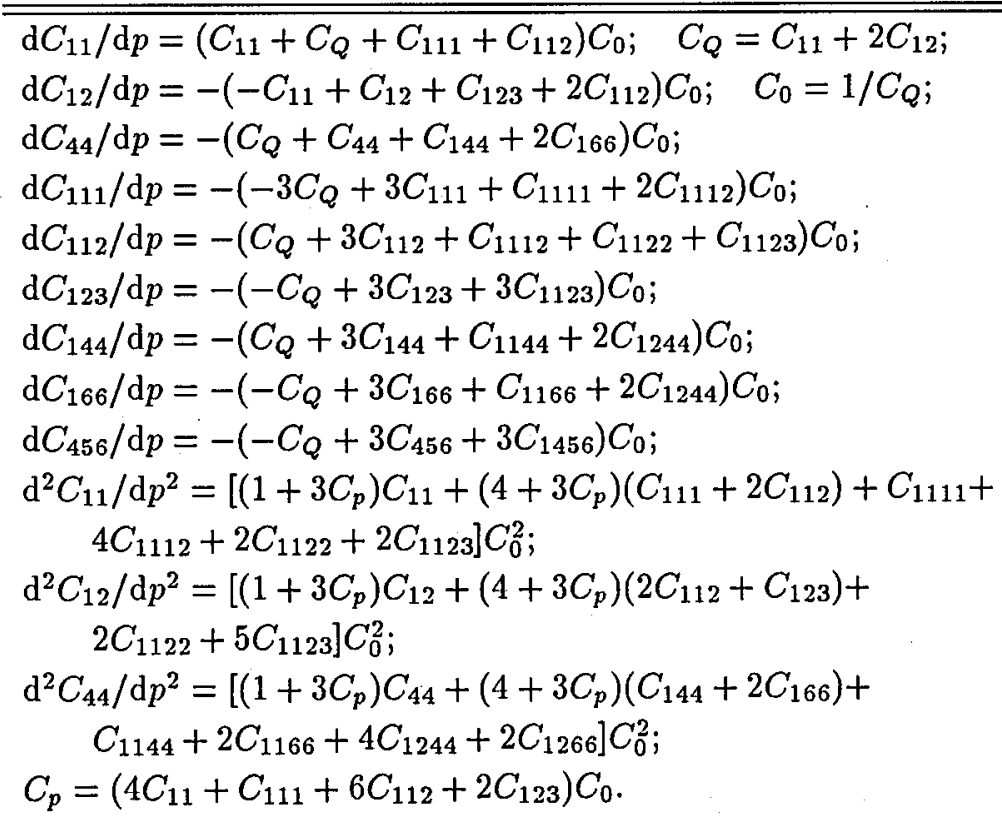


TABLE V

Expressions for partial contractions of the fourth order elastic constants.

\begin{tabular}{l}
\hline$Y_{11}=C_{1111}+4 C_{1112}+2 C_{1122}+2 C_{1123}$ \\
$Y_{12}=2 C_{1112}+2 C_{1122}+5 C_{1123}$ \\
$Y_{44}=C_{1144}+2 C_{1166}+4 C_{1244}+2 C_{1266}$.
\end{tabular}

TABLE XI

The second order pressure derivatives of the second order elastic constants in $10^{-10} \mathrm{dyn} / \mathrm{cm}^{2}$ and partial contractions in $10^{13} \mathrm{dyn} / \mathrm{cm}^{2}$.

\begin{tabular}{l|c|c|c|r|r|r|c}
\hline \hline $\mathrm{Sub}$. & $\frac{\mathrm{d}^{2} C_{11}}{d p^{2}}$ & $\frac{\mathrm{d}^{2} C_{12}}{d p^{2}}$ & $\frac{\mathrm{d}^{2} C_{44}}{\mathrm{~d} p^{2}}$ & $Y_{11}$ & $Y_{12}$ & $Y_{44}$ & Ref. \\
\hline $\mathrm{LiF}$ & -14.24 & -12.14 & -3.30 & -1158 & -1189 & -259.9 & this work \\
$\mathrm{LiCl}$ & -8.30 & -9.45 & -2.32 & -144.7 & -158.9 & -33.77 & this work \\
$\mathrm{LiBr}$ & -6.100 & -8.67 & -2.00 & -80.65 & -92.17 & -19.30 & this work \\
$\mathrm{LiI}$ & -5.57 & -10.07 & -2.28 & -50.76 & -59.96 & -12.53 & this work \\
$\mathrm{NaF}$ & -2.85 & -4.33 & -1.01 & -157.9 & -182.5 & -38.32 & this work \\
& -7.2 & -0.8 & 0.2 & & & & {$[47]$} \\
$\mathrm{NaCl}$ & -1.22 & -3.79 & -0.64 & -27.39 & -40.32 & -7.985 & this work \\
& -9.4 & -0.4 & -0.6 & & & & {$[47]$} \\
$\mathrm{NaBr}$ & 3.96 & -3.01 & -0.32 & -10.86 & -21.39 & -4.006 & this work \\
& -6.2 & -3.4 & -0.8 & & & & {$[47]$} \\
$\mathrm{NaI}$ & -6.78 & -3.24 & -0.24 & -5.15 & -13.43 & -2.468 & this work \\
& -10.4 & -3.4 & -1.0 & & & & {$[47]$} \\
$\mathrm{KF}$ & -0.49 & -4.35 & -0.89 & -52.07 & -68.48 & -14.04 & this work \\
$\mathrm{KCl}$ & -4.67 & -4.46 & -0.76 & -14.02 & -25.26 & -5.105 & this work \\
$\mathrm{KBr}$ & -8.63 & -3.13 & -0.31 & -3.689 & -13.42 & -2.582 & this work \\
$\mathrm{KI}$ & -12.89 & -3.04 & -0.16 & -0.449 & -8.292 & -1.566 & this work \\
& -12.7 & -1.6 & -1.08 & & & & {$[32]$} \\
$\mathrm{RbF}$ & -1.39 & -3.88 & -0.71 & -29.95 & -44.48 & -8.970 & this work \\
$\mathrm{RbCl}$ & -8.13 & -3.67 & -0.50 & -5.839 & -16.22 & -3.228 & this work \\
& -11.3 & -0.3 & -1.1 & 11.20 & -0.20 & 0.16 & {$[31]$} \\
$\mathrm{RbBr}$ & -13.39 & -2.09 & 0.02 & 1.839 & -7.243 & -1.337 & this work \\
& -15.6 & -3.5 & -1.2 & 9.10 & -0.9 & 0.18 & {$[31]$} \\
$\mathrm{RbI}$ & -18.26 & -1.65 & 0.24 & 3.476 & -4.204 & -0.747 & this work \\
$\mathrm{LiCN}$ & -18.4 & -2.3 & -1.3 & 7.7 & -0.41 & 0.21 & {$[31]$} \\
$\mathrm{NaCN}$ & -5.39 & -4.58 & -1.16 & -945.3 & -972.2 & -207.5 & this work \\
$\mathrm{RbCN}$ & -0.11 & -1.79 & -0.30 & -106.9 & -131.1 & -25.39 & this work \\
& 1.13 & -1.67 & -0.29 & -56.84 & -78.67 & -15.10 & this work \\
& & & & -32.11 & -52.55 & -9.817 & this work
\end{tabular}




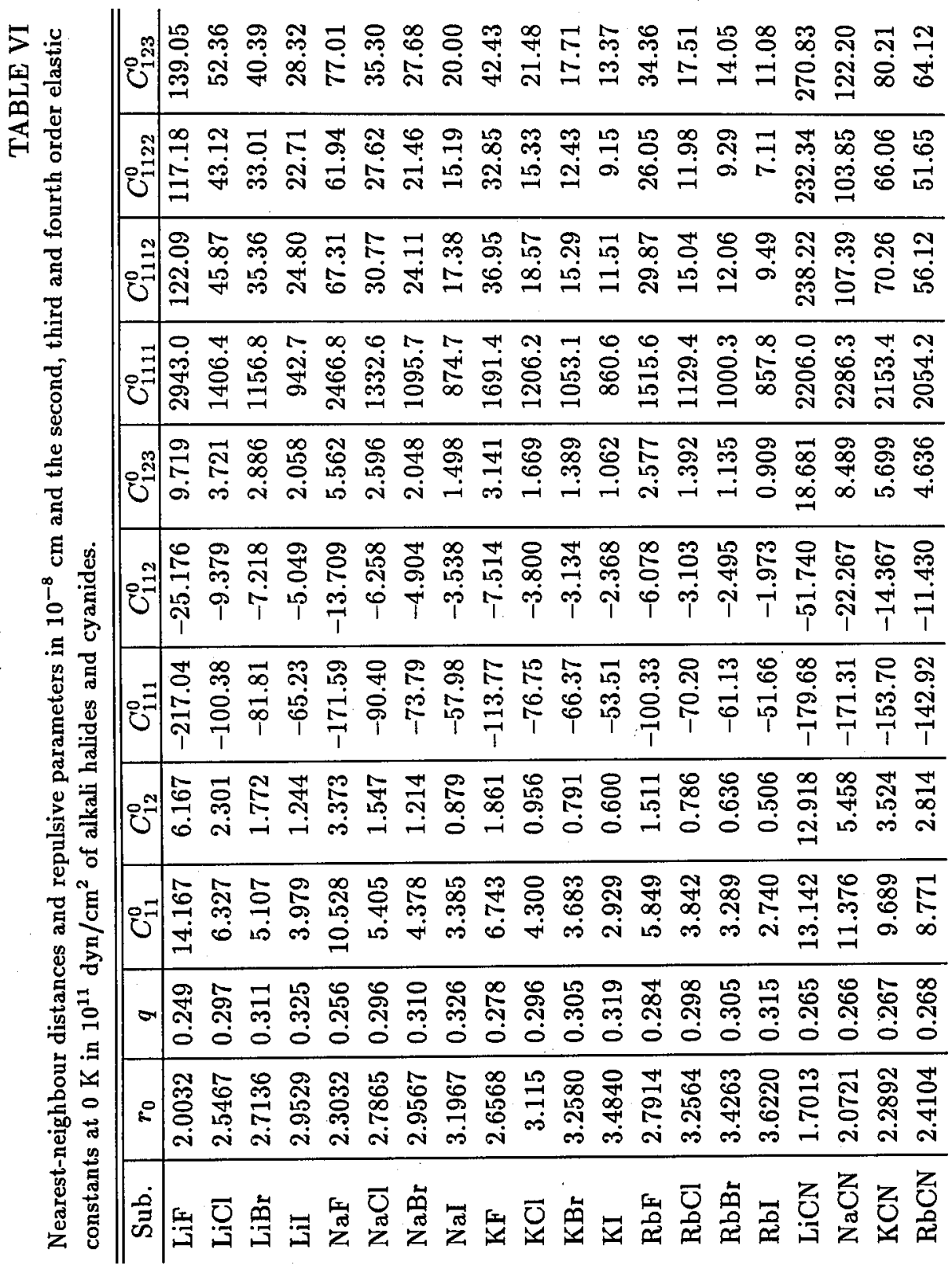




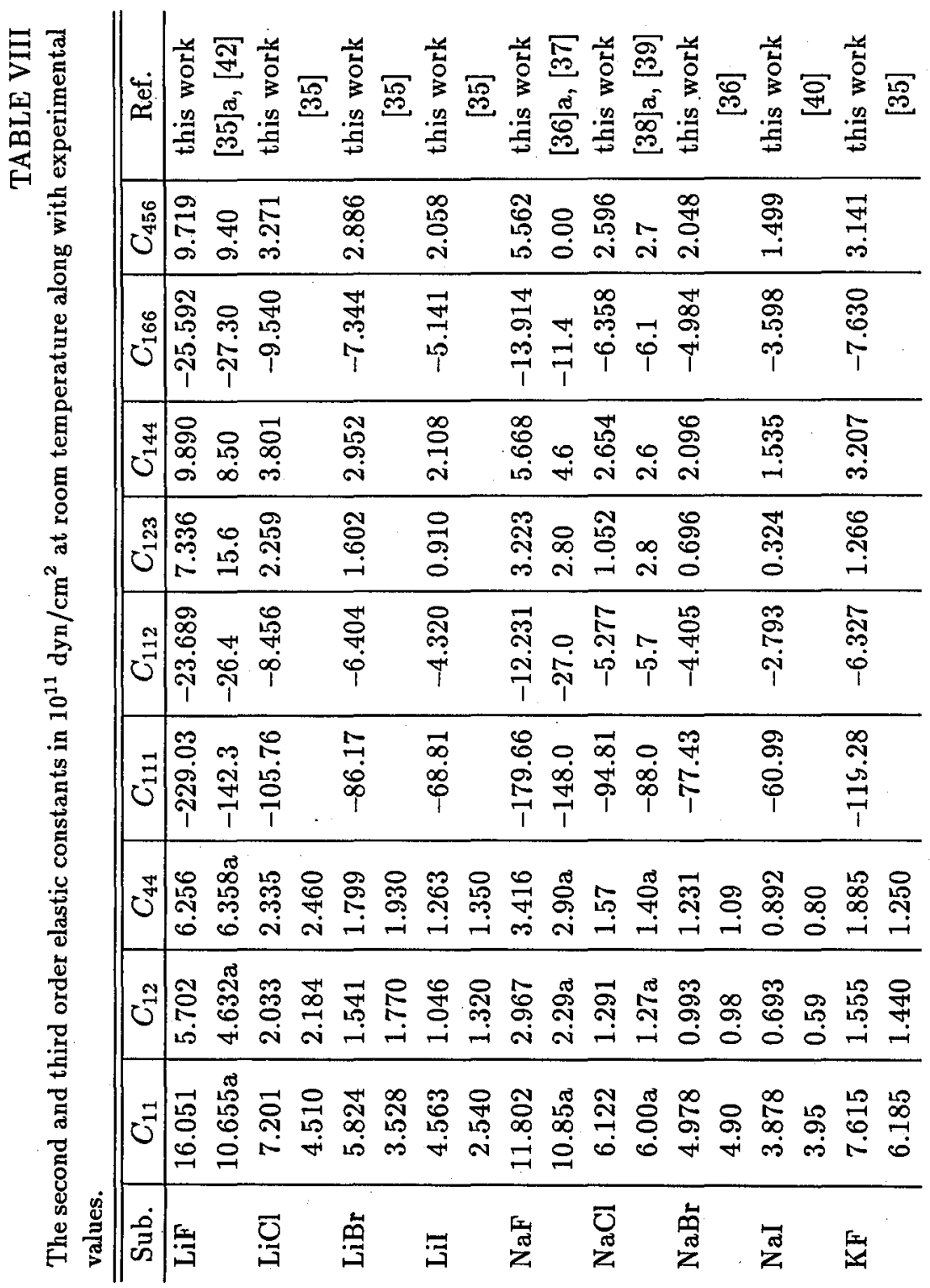




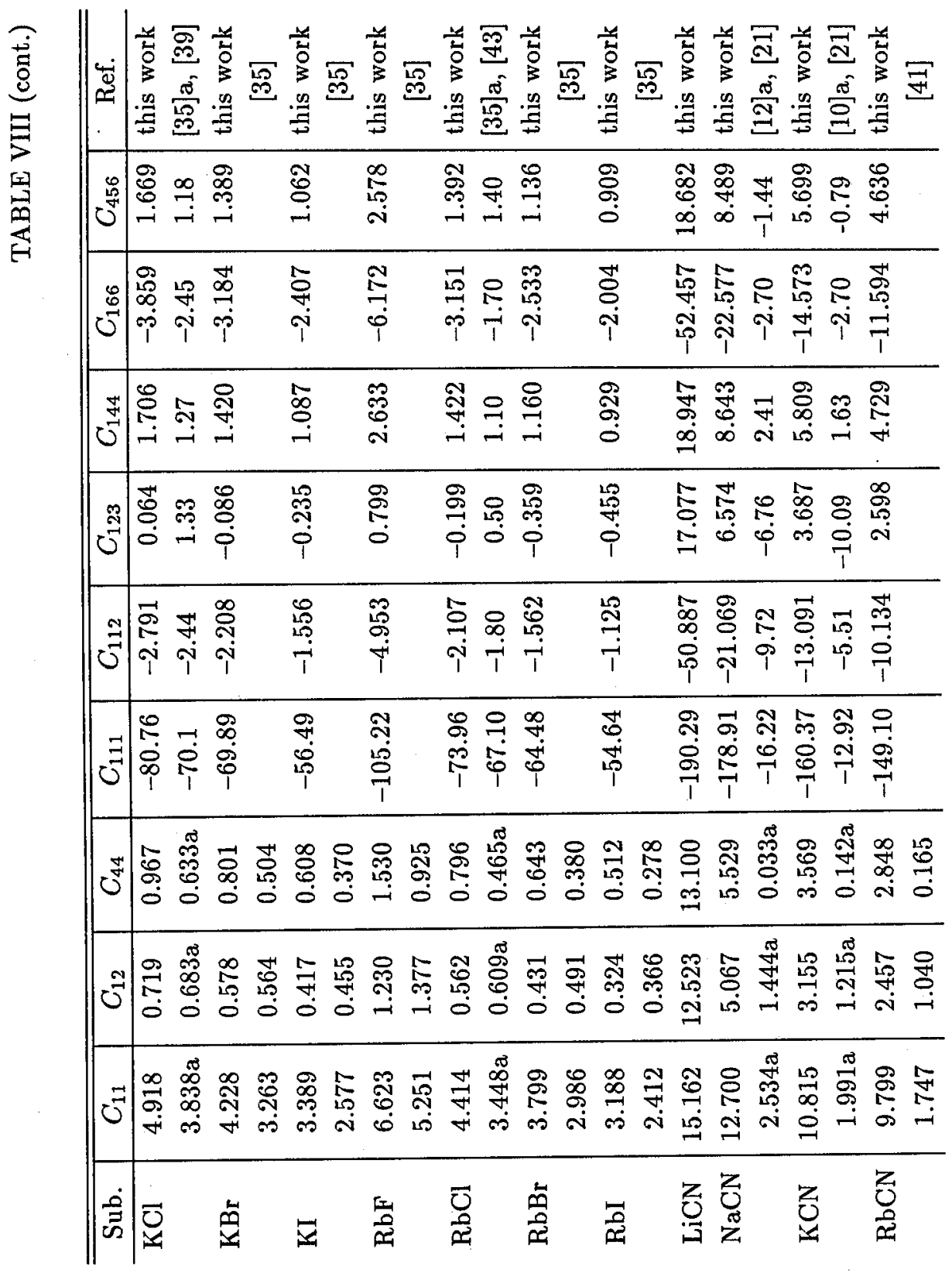




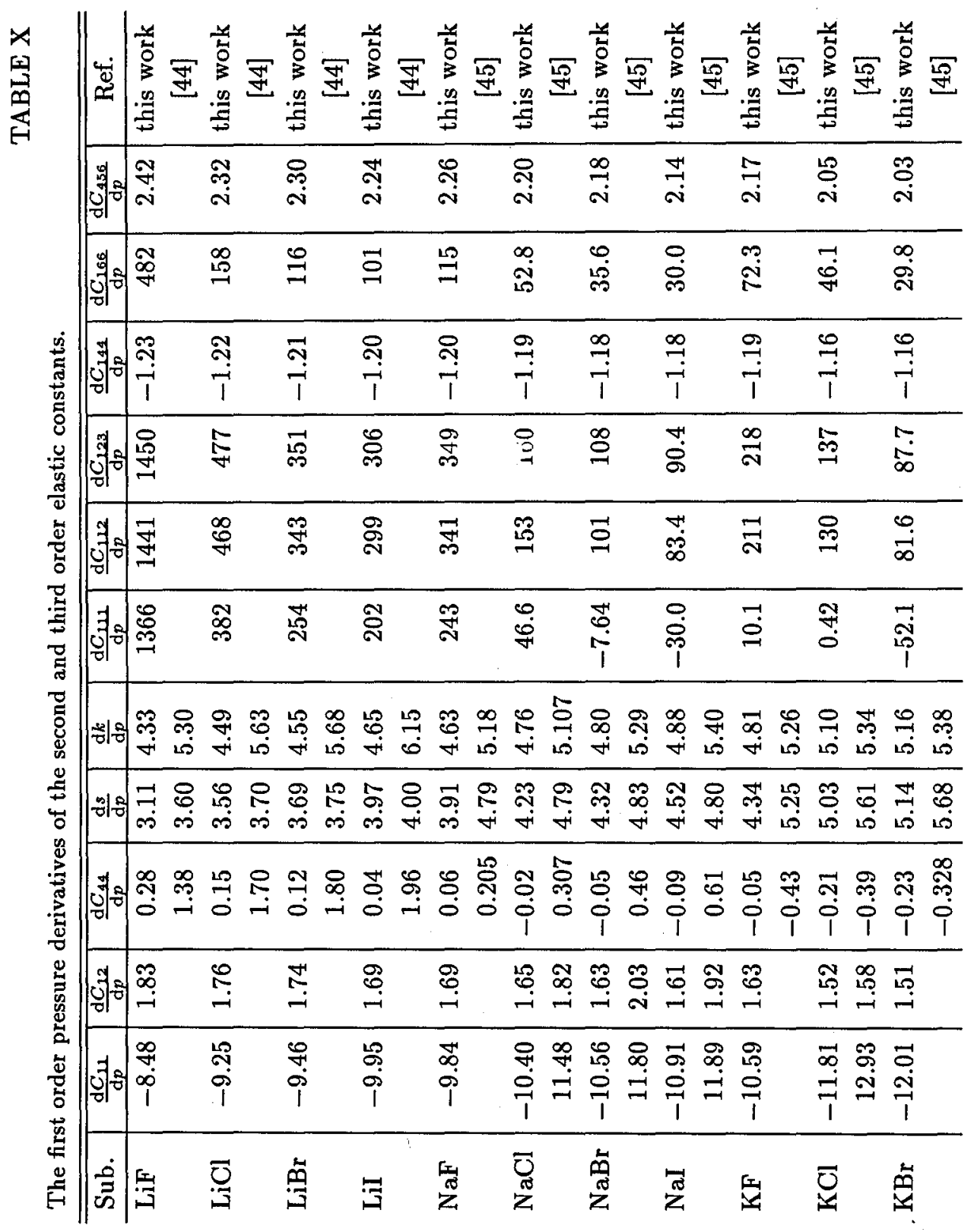




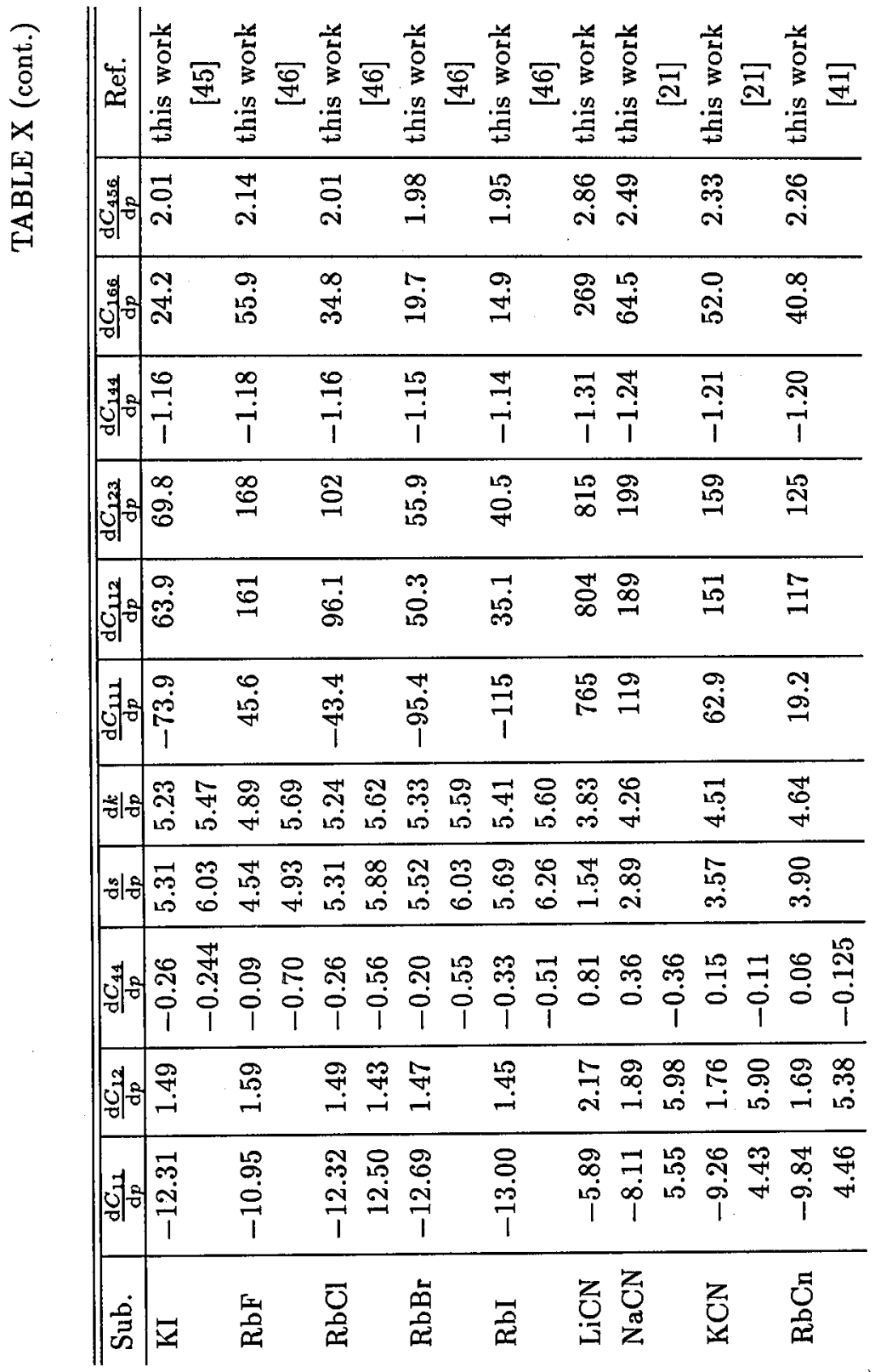



氞 影央

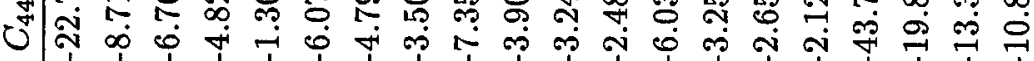
ఫ我

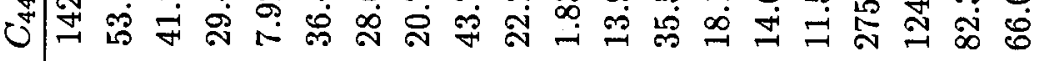

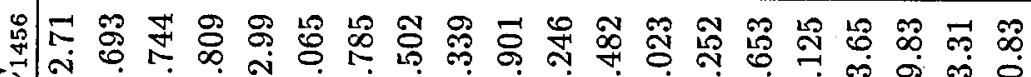

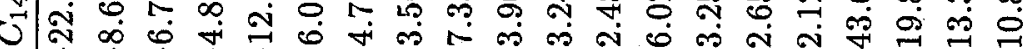

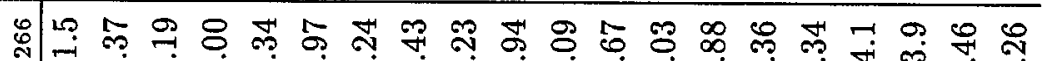

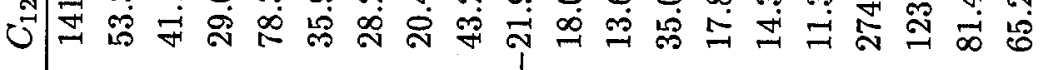

莺 Uال

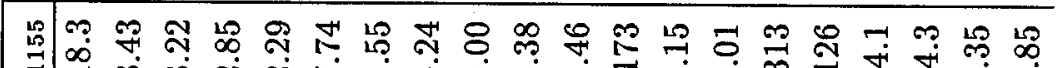

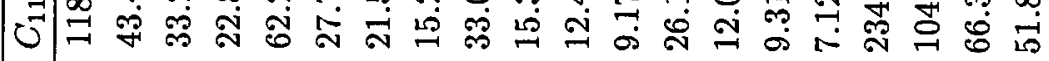

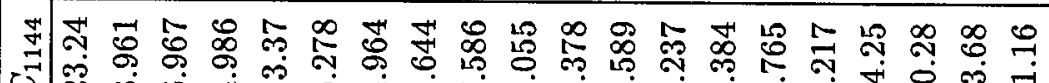
त

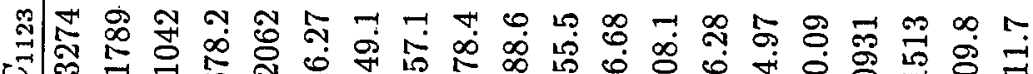

絰

$\Xi$

疍

สิ $\infty$ \% 0 \%

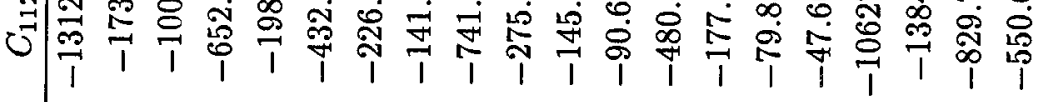

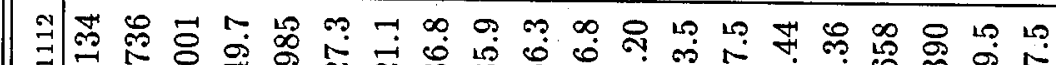
苞

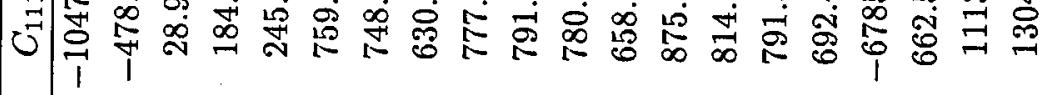


TABLE VII

Temperature coefficients $\left(F_{n}\right)$ and natural frequency $\left(\omega_{0}\right)$ in $10^{13} \mathrm{~s}^{-1}$.

\begin{tabular}{l|c|c|c|c|c|c|c|c}
\hline \hline $\mathrm{Sub}$ & $F_{1}$ & $F_{2}$ & $F_{3}$ & $F_{4}$ & $F_{5}$ & $F_{6}$ & $F_{7}$ & $\omega_{0}$ \\
\hline $\mathrm{LiF}$ & -15.92 & 133.0 & -1247 & 460.9 & 4.915 & -32.33 & 230.4 & 7.680 \\
$\mathrm{LiCl}$ & -16.97 & 152.1 & -1519 & 473.1 & 4.520 & -31.42 & 236.5 & 5.237 \\
$\mathrm{LiBr}$ & -17.26 & 157.6 & -1602 & 475.2 & 4.405 & -31.16 & 237.6 & 4.593 \\
$\mathrm{LiI}$ & -17.97 & 171.4 & -1812 & 477.7 & 4.130 & -30.29 & 238.8 & 4.096 \\
$\mathrm{NaF}$ & -17.80 & 167.9 & -1759 & 477.4 & 4.198 & -30.52 & 238.7 & 4.698 \\
$\mathrm{NaCl}$ & -18.62 & 184.3 & -2019 & 477.3 & 3.880 & -29.38 & 238.6 & 3.142 \\
$\mathrm{NaBr}$ & -18.86 & 189.3 & -2098 & 476.5 & 3.787 & -29.01 & 238.3 & 2.562 \\
$\mathrm{NaI}$ & -19.39 & 200.3 & -2279 & -473.7 & 3.587 & -28.18 & 236.8 & 2.223 \\
$\mathrm{KF}$ & -18.90 & 190.1 & -2110 & 476.4 & 3.773 & -28.95 & 238.2 & 3.559 \\
$\mathrm{KCl}$ & -20.79 & 230.7 & -2803 & 459.9 & 3.085 & -25.80 & 229.9 & 2.476 \\
$\mathrm{KBr}$ & -21.12 & 238.3 & -2939 & 455.3 & 2.970 & -25.20 & 227.6 & 1.965 \\
$\mathrm{KI}$ & -21.60 & 249.2 & -3138 & 448.2 & 2.812 & -24.35 & 224.1 & 1.688 \\
$\mathrm{RbF}$ & -19.44 & 201.1 & -2295 & 473.4 & 3.571 & -28.10 & 236.7 & 3.053 \\
$\mathrm{RbCl}$ & -21.61 & 249.5 & -3143 & 448.0 & 2.809 & -24.32 & 224.0 & 2.041 \\
$\mathrm{RbBr}$ & -22.22 & 263.8 & -3409 & 437.9 & 2.615 & -23.22 & 218.9 & 1.499 \\
$\mathrm{RbI}$ & -22.74 & 276.4 & -3650 & 428.3 & 2.455 & -22.27 & 214.1 & 1.258 \\
$\mathrm{LiCN}$ & -12.71 & 81.56 & -597.4 & 371.3 & 5.852 & -31.41 & 185.6 & 8.031 \\
$\mathrm{NaCN}$ & -15.42 & 124.3 & -1127 & 452.1 & 5.097 & -32.57 & 226.0 & 4.606 \\
$\mathrm{KCN}$ & -16.97 & 152.0 & -1519 & 473.1 & 4.521 & -31.48 & 236.5 & 3.746 \\
$\mathrm{RbCN}$ & -17.79 & 167.8 & -1757 & 477.4 & 4.200 & -30.52 & 238.7 & 3.168 \\
& & & & & & & &
\end{tabular}

\section{References}

[1] M. Nastar, F. Williame, Phys. Rev. B 51, 6896 (1995).

[2] C.Z. Wang, K.M. Ho, Phys. Rev. Lett. 66, 189 (1991); ibid. 71, 1184 (1993).

[3] Ji-D. Dai, J. Appl. Phys. 75, 4716 (1994).

[4] S. Subramanian, R. Sooryakumar, G.A. Prinz, B.T. Jonker, Y.U. Idzerda, Phys. Rev. B 49, 17319 (1994).

[5] G.A. Saunders, H.B. Senin, H.A.A. Sidek, J. Pelzl, Phys. Rev. B 48, 15801 (1993).

[6] D. Wagner, V.M. Zeverev, V.P. Silin, M. Thor, JETP Lett. 56, 595 (1992).

[7] D. Gerlich, J. Appl. Phys. 67, 3287 (1990).

[8] S. Lehri, J. Shanker, Phys. Status Solidi B 141, 97 (1987).

[9] U.C. Srivastava, Phys. Status Solidi B 100, 641 (1980); Phys. Rev. B 21, 2602 (1980).

[10] S. Haussühl, Solid State Commun. 13, 147 (1973).

[11] W. Krasser, U. Buchenan, S. Haussühl, Solid State Commun. 18, 287 (1976). 
[12] A. Haussühl, J. Eckstein, K. Reckor, F. Wallsofen, Acta Crystallogr. A 33, 347 (1977):

[13] S.K. Satiza, C.H. Wang, J. Chem. Phys. 70, 4437 (1979).

[14] K. Stronner, W. Henkel, H.D. Hochheiner, M. Cardona, Solid State Commun. 45, 567 (1983).

[15] K. Walasek, K. Lukierska-Walasek, Phys. Rev. B 49, 9937 (1994).

[16] S. Mori, Y. Hiki, J. Phys. Soc. Jpn. 45, 14 (1978).

[17] Y. Hiki, Higher Order Elastic Constants, Annual Review of Material Science Japan, Vol. 11, Tokyo 1981.

[18] K.P. Thakur, J. Phys. Chem. Solids 41, 465 (1980).

[19] S. Lehri, M.P. Verma, Phys. Status Solidi B 98, 789 (1980).

[20] S.S. Bedi, M.P. Verma, Phys. Stalus Solidi B 97, 203 (1980).

[21] S. Haussühl, W. Michaelis, Acta Crystallogr. A 35, 240 (1979).

[22] R.K. Varshney, J. Shanker, Phys. Status Solidi B 129, 61 (1985).

[23] F. Birch, Phys. Rev. 71, 809 (1947).

[24] K. Brügger, Phys. Rev. 133, A 1611 (1964).

[25] G. Leibfried, H. Hahn, Z. Phys. 150, 197 (1958).

[26] G. Leibfried, W. Ludwig, Solid State Physics, Vol. 12, Academic Press, New York 1961.

[27] M. Börn, J.M. Mayer, Z. Phys. 71, 1 (1932).

[28] C. Kittel, Introduction to Solid State Physics, John Wiley, New York 1981.

[29] P.B. Ghate, Phys. Rev. 139, A1666 (1965); Phys. Status Solidi B 14, 325 (1966).

[30] G.R. Barsch, Z.P. Chang, J. Appl. Phys. 39, 3276 (1968).

[31] Z.P. Chang, G.R. Barsch, J. Phys. Chem. Solids 32, 27 (1971).

[32] G.R. Barsch, H.E. Shull, Phys. Status Solidi B 43, 637 (1971).

[33] M.P. Tosi, Solid State Physics, Vol. 16, Academic Press, New York 1965.

[34] P. Mohazzabi, Solid Stale Commun. 63, 61 (1987).

[35] S. Haussühl, Z. Phys. 159, 223 (1960).

[36] J.T. Lewis, A. Lehoczky, C.V. Briscoe, Phys. Rev. 161, A877 (1967).

[37] W.A. Bensch, Phys. Rev. B 6, 1504 (1972).

[38] H. Spetzler, C.G. Sammis, R.J.O. Connel, J. Phys. Chem. Solids 33, 1727 (1972).

[39] Z.P. Chang, Phys. Rev. 140, A1788 (1965).

[40] R. Dalven, C.W. Carland, J. Chem. Phys. 30, 346 (1959).

[41] S. Haussühl, Solid State Commun. 32, 181 (1979).

[42] J.R. Drabble, R.E.B. Strathen, Proc. Phys. Soc. 92, 1090 (1967).

[43] S. Rolandson, Phys. Status Solidi B 52, 643 (1972).

[44] K.O. Mclean, C.S. Smith, J. Phys. Chem. Solids 33, 279 (1972).

[45] R.W. Roberts, C.S. Smith, J. Phys. Chem. Solids 31, 619 (1970).

[46] R.W. Roberts, C.S. Smith, J. Phys. Chem. Solids 31, 2397 (1970).

[47] S. Hart, P.H. Greenwood, Solid State Commun. 46, 161 (1983). 